\section{(2) OPEN ACCESS}

\title{
TNF is a homoeostatic regulator of distinct epigenetically primed human osteoclast precursors
}

\author{
Cecilia Ansalone (1) , John Cole, Sabarinadh Chilaka, Flavia Sunzini, Shatakshi Sood, \\ Jamie Robertson 조 , Stefan Siebert, lain B McInnes, Carl S Goodyear
}

\begin{abstract}
Handling editor Josef $S$ Smolen

- Additional material is published online only. To view, please visit the journal online (http://dx.doi.org/10.1136/ annrheumdis-2020-219262).
\end{abstract}

Institute of Infection, Immunity and Inflammation, University of Glasgow, Glasgow, UK

\section{Correspondence to}

Professor Carl S Goodyear, Institute of Infection, Immunity and Inflammation, University of Glasgow, Glasgow G12 8TA, UK:

carl.goodyear@glasgow.ac.uk

Part of this study was previously presented at the 2017 ACR/ ARHP Annual Meeting, Arthritis Rheumatol. 2017; 69 (suppl 10).

Received 8 October 2020 Revised 31 December 2020 Accepted 25 January 2021 Published Online First 10 March 2021

\section{ABSTRACT}

Objectives Circulating myeloid precursors are responsible for post-natal osteoclast (OC) differentiation and skeletal health, although the exact human precursors have not been defined. Enhanced osteoclastogenesis contributes to joint destruction in rheumatoid arthritis (RA) and tumour necrosis factor (TNF) is a well-known pro-osteoclastogenic factor. Herein, we investigated the interplay between receptor activator of nuclear factor kappa-B ligand (RANK-L), indispensable for fusion of myeloid precursors and the normal development of $\mathrm{OCS}$, and TNF in directing the differentiation of diverse pre-OC populations derived from human peripheral blood.

Methods Flow cytometric cell sorting and analysis was used to assess the potential of myeloid populations to differentiate into OCs. Transcriptomic, epigenetic analysis, receptor expression and inhibitor experiments were used to unravel RANK-L and TNF signalling hierarchy.

Results TNF can act as a critical homoeostatic regulator of $\mathrm{CD}_{14}{ }^{+}$monocyte (MO) differentiation into OCs by inhibiting osteoclastogenesis to favour macrophage development. In contrast, a distinct previously

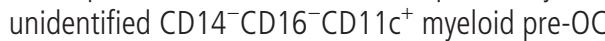
population was exempt from this negative regulation. In healthy $\mathrm{CD}_{14}{ }^{+} \mathrm{MOs}$, TNF drove epigenetic modification of the RANK promoter via a TNFR1-IKK $\beta$-dependent pathway and halted osteoclastogenesis. In a subset of patients with RA, CD14 ${ }^{+}$MOs exhibited an altered epigenetic state that resulted in dysregulated TNFmediated OC homoeostasis.

Conclusions These findings fundamentally redefine the relationship between RANK-L and TNF. Moreover, they have identified a novel pool of human circulating non-MO OC precursors that unlike MOs are epigenetically preconditioned to ignore TNF-mediated signalling. In RA, this epigenetic preconditioning occurs in the MO compartment providing a pathological consequence of failure of this pathway.

\section{INTRODUCTION}

Osteoclasts (OCs) are polykarion bone-resorbing cells that can be derived from either yolk sac erythro-myeloid progenitors or bone marrow/ circulating monocyte (MO) precursors ${ }^{1}$ supported by the receptor activator of nuclear factor kappa-B (RANK) receptor and tumour necrosis factor (TNF) family cytokine RANK-ligand (RANK-L). ${ }^{2} 3$ Circulating MO also have the capacity to differentiate into macrophages $(\mathrm{M} \varphi)$ or dendritic cells (DCs). ${ }^{45}$ Recently, human ontogenetic and transcriptomic studies have re-classified DCs, MO, $\mathrm{MO}$-derived cells and tissue resident $\mathrm{M} \varphi$ based on

\section{Key message}

What is already known about this subject?

- OC differentiation and maturation from myeloid precursors relies on receptor activator of nuclear factor kappa-B (RANK) signalling and murine studies suggest that tumour necrosis factor (TNF) is a potent coactivator.

- One of the gold standard therapy for rheumatoid arthritis includes blocking TNF although a consistent portion of patients do not respond and display progressive joint destruction.

What does this study add?

- We have discovered a novel non-monocyte (MO) osteoclast (OC) precursor population in the human peripheral blood and demonstrated its epigenetic and transcriptomic imprint towards $\mathrm{OC}$ differentiation.

- We have demonstrated that TNF can act as a homoeostatic regulator of classical peripheral CD14 ${ }^{+}$MOs by inhibiting their differentiation into OCs to favour macrophages and showed how this mechanism is epigenetically perturbated in a portion of patients with rheumatoid arthritis (RA) with active disease.

How might this impact on clinical practice or future developments?

- These data provide an important insight into the cellular and epigenetic heterogeneity in RA and can be used to develop alternative therapeutics for those patients that do not respond to current therapies.

their differentiation from specific precursor cells. ${ }^{67}$ While murine studies have identified specific OC myeloid precursors ${ }^{8}$ that play a crucial role in postnatal OC differentiation in vivo, ${ }^{1}$, it is unclear whether specific non-MO circulating OC precursors exist in humans. Moreover, how such precursors respond to competing differentiating and activating cytokine signals and select their eventual cell fate is poorly understood.

Murine studies have shown that in combination with RANK-L, TNF is a direct maturation/activation stimulus of OC precursors. ${ }^{9-11}$ It has been assumed that TNF mediates equivalent actions across human OC precursors. Consistent with this notion, TNF is one of the main mediators of joint inflammation in inflammatory diseases such 
as rheumatoid arthritis (RA), which is associated with articular damage and systemic bone loss. ${ }^{12} 13$ Furthermore, in the clinical setting, treatment with TNF inhibitors has been shown to reduce articular erosion. ${ }^{14}$ However, the precise effects of TNF acting directly on human myeloid/MO/OC precursors remains illdefined. Inflamed tissues, both in acute or chronic states, exhibit elevated levels of TNF, usually associated with MO recruitment and maturation even in the presence of RANK-L. ${ }^{15}$ It is unclear why in environments that are favourable to osteoclastogenesis, a preponderance of infiltrating myeloid precursors does not differentiate down the OC lineage.

Herein, we report the existence of a human $\mathrm{CD} 14^{-} \mathrm{C}$ $\mathrm{D} 16^{-} \mathrm{CD} 11 \mathrm{c}^{+}$myeloid precursor population that is epigenetically predisposed to rapidly differentiate into OCs. Notably, this population is unresponsive to a previously unrecognised homoeostatic TNF-mediated signal that fundamentally governs cell fate decisions in $\mathrm{CD} 14^{+} \mathrm{MOs}$ that favours $\mathrm{M} \varphi$ development. Moreover, we provide evidence that this effect is mediated by TNF via epigenetic regulation of the RANK promoter in circulating $\mathrm{CD} 14^{+} \mathrm{MOs}$ and that this pathway is perturbed in RA.

\section{MATERIALS AND METHODS}

Detailed experimental procedures and analyses are provided in online supplemental files.

\section{RESULTS}

\section{Distinct epigenetically primed $\mathrm{OC}$ precursors in human blood}

Circulating $\mathrm{CD} 14^{+} \mathrm{MOs}$ are regarded as classical OC precursors, ${ }^{16}$ but the existence of a distinct circulating human precursor is not known. To investigate the osteoclastogenic potential of circulating human myeloid cells we used fluorescence-activated cell sorting (figure $1 \mathrm{~A}$ ) to purify circulating $\mathrm{MO}$ subsets (classical $\mathrm{Lin}^{-} \mathrm{HLA}^{-} \mathrm{DR}^{+} \mathrm{CD} 14^{+} \mathrm{CD} 16^{-}$, intermediate $\mathrm{Lin}^{-} \mathrm{HLA}^{-} \mathrm{DR}^{+} \mathrm{C}-$ $\mathrm{D} 14^{+} \mathrm{CD} 16^{+}$and non-classical $\mathrm{Lin}^{-} \mathrm{HLA}^{-} \mathrm{DR}^{+} \mathrm{CD} 14^{\mathrm{dim}} \mathrm{CD} 16^{++}$) and other myeloid cells $\left(\mathrm{Lin}^{-} \mathrm{HLA}^{-} \mathrm{DR}^{+} \mathrm{CD} 14^{-} \mathrm{CD} 16^{-}\right.$). Culture of these populations with macrophage-colony stimulating factor (M-CSF) and RANK-L verified that classical MOs differentiate into mature OCs while intermediate and non-classical populations only produced few and variable numbers of small $\mathrm{OCs}^{17}$ (figure 1B,C). Intriguingly, purified $\mathrm{Lin}^{-} \mathrm{HLA}^{-} \mathrm{DR}^{+} \mathrm{C}$ $\mathrm{D} 14^{-} \mathrm{CD} 16^{-}$myeloid cells differentiated into OCs, with numbers comparable to classical $\mathrm{CD} 14^{+} \mathrm{MOs}$ (figure $1 \mathrm{~B}, \mathrm{C}$ ). $\mathrm{Lin}^{-} \mathrm{HLA}^{-} \mathrm{DR}^{+} \mathrm{CD} 14^{-} \mathrm{CD} 16^{-}$myeloid cells can be subdivided via $\mathrm{CD} 11 \mathrm{c}$ expression into populations that contain conventional pre-DCs $\left(\mathrm{CD} 14^{-} \mathrm{CD} 16^{-} \mathrm{CD} 11 \mathrm{c}^{+}\right)$and plasmacytoid DCs $\left(\mathrm{CD} 14^{-} \mathrm{CD} 16^{-} \mathrm{CD} 11 \mathrm{c}^{-}\right)^{7}$; only the $\mathrm{CD} 14^{-} \mathrm{CD} 16^{-} \mathrm{CD} 11 \mathrm{c}^{+}$ population was able to adhere and differentiate into mature OCs (figure 1D).

The in vivo kinetics of osteoclastogenesis from precursors to a mature OC are not clear in humans, however, murine studies have shown that preconditioned cells can mature into OCs within 48 hours. ${ }^{18}$ The in vitro generation of a mature OCs from circulating $\mathrm{CD}_{14}{ }^{+} \mathrm{MOs}$ or in vitro differentiated MO-derived pre/immature DCs or M $\varphi$ takes in excess of 7-14 days. ${ }^{5} 1920 \mathrm{We}$ hypothesised that this reflects the non-preconditioned state of the precursor and thus time is required for in vitro cell differentiation/trans-differentiation. In support of this, $\mathrm{CD} 14^{+} \mathrm{MOs}$ are preincubated overnight with M-CSF to generate CD14 ${ }^{+}$ pre-OCs. This preincubation leads to upregulation of RANK and CSF1R (M-CSF receptor) transcripts (figure 1E), ${ }^{21}$ and increased tri-methylation of histone $\mathrm{H} 3$ at lysine 4 (H3K4me3) in the RANK promoter (figure 1E), indicative of a transcriptionally active epigenetic state. ${ }^{22}$ In comparison, immediate ex vivo evaluation of the identified $\mathrm{CD} 14^{-} \mathrm{CD} 16^{-} \mathrm{CD} 11 \mathrm{c}^{+}$ myeloid population revealed that they have higher levels of RANK transcript and decreased levels of CSF1R compared with classical CD14 ${ }^{+}$MOs (figure 1F). This was associated with an increased level of $\mathrm{H} 3 \mathrm{~K} 4 \mathrm{me} 3$ at the RANK promoter but less at the CSF1R promoter of $\mathrm{CD} 14^{-} \mathrm{CD} 16^{-} \mathrm{CD} 11 \mathrm{c}^{+}$myeloid population compared with donor-matched $\mathrm{CD} 14^{+} \mathrm{MOs}$ (figure $1 \mathrm{~F}$ ). Pre-OCs from both $\mathrm{CD} 14^{+} \mathrm{MOs}$ and $\mathrm{CD} 14^{-} \mathrm{CD} 16^{-} \mathrm{CD} 11 \mathrm{c}^{+}$ cells were generated by M-CSF overnight incubation. Assessment of OC differentiation 72 hours post-RANK-L stimulation, revealed that while $\mathrm{CD} 14^{+}$pre-OCs produce few small OCs at this time point, $\mathrm{CD} 11 \mathrm{c}^{+}$pre-OCs rapidly differentiate into macroscopically larger OCs, with numbers significantly higher than those differentiated from donor-matched $\mathrm{CD} 14^{+}$pre-OCs (figure $1 \mathrm{G}$ ). Taken together, these results suggest that the circulating $\mathrm{CD} 14^{-} \mathrm{CD} 16^{-} \mathrm{CD} 11 \mathrm{c}^{+}$myeloid population contains $\mathrm{OC}$ precursors that are in an epigenetically precommitted state to rapidly differentiate into mature OCs.

TNF over-rides RANKL-driven osteoclastogenesis of CD14 ${ }^{+}$ circulating precursors but not $\mathrm{CD}_{14} \mathrm{CDD}^{-} 6^{-} \mathrm{CD} 11 \mathrm{c}^{+}$precursors TNF is a well-known pro-osteoclastogenic factor, both in vitro $^{9} 1023$ and in vivo. ${ }^{24-26}$ However, nothing is known about how human circulating precursors respond to simultaneous exposure to TNF family member cytokines, as would be expected in a physiological setting. Therefore, we simultaneously stimulated human $\mathrm{CD} 14^{+}$pre-OCs and $\mathrm{CD} 11 \mathrm{c}^{+}$pre-OCs with RANK-L and TNF. Unexpectedly, we found that synchronised stimulation of CD14 ${ }^{+}$pre-OCs with RANK-L and TNF resulted in substantial inhibition of osteoclastogenesis (figure 2A,B). The resulting cells exhibited $\mathrm{M} \varphi$ morphology, although dissimilar to either regulatory M-CSF-driven $\mathrm{M} \varphi(\mathrm{M}-\mathrm{M} \varphi)$ or pro-inflammatory GM-CSF-driven $\mathrm{M} \varphi(\mathrm{GM}-\mathrm{M} \varphi$ ) (online supplemental figure S1).

In comparison to what was observed in $\mathrm{CD} 14^{+}$pre-OCs, TNF was unable to inhibit the generation of mature OCs derived from CD11 $\mathrm{c}^{+}$pre-OCs (figure 2A,B). Extending the duration of differentiation to 14 days, we found that TNF completely abrogated the resorptive activity of $\mathrm{CD} 14^{+}$pre-OCs but had no effect on $\mathrm{CD} 11 \mathrm{c}^{+}$pre-OCs resorption (figure $\left.2 \mathrm{C}, \mathrm{D}\right)$. In order to demonstrate that $\mathrm{CD} 11 \mathrm{c}^{+}$pre-OCs were not completely unresponsive to TNF, the secretion of relevant cytokines was evaluated. Notably, TNF stimulation resulted in the increased secretion of interferon- $\gamma$ in $\mathrm{CD} 11 \mathrm{c}^{+}$pre-OCs but not $\mathrm{CD} 14^{+}$pre-OCs (online supplemental figure S2). Conversely, TNF stimulation resulted in the secretion of interleukin (IL)-12, IL-1 $\beta$ and IL- 6 in $\mathrm{CD} 14^{+}$pre-OCs but not $\mathrm{CD} 11 \mathrm{c}^{+}$pre-OCs (online supplemental figure S2). Thus, circulating $\mathrm{CD} 14^{-} \mathrm{CD} 16^{-} \mathrm{CD} 11 \mathrm{c}^{+}$precursors and $\mathrm{CD} 14^{+} \mathrm{MOs}$ display a fundamental difference in their response to TNF, with $\mathrm{CD} 14^{-} \mathrm{CD} 16^{-} \mathrm{CD} 11 \mathrm{c}^{+}$precursors able to differentiate into mature and functional OCs.

\section{TNF-mediated epigenetic modification of the RANK promoter controls RANK transcription and expression in CD14 ${ }^{+}$-derived OC precursors}

To further explore the unexpected inhibition of osteoclastogenesis by TNF, we extended our cellular and molecular characterisation of $\mathrm{CD} 14^{+}$pre-OCs. Increasing RANK-L concentration to potentially outcompete the simultaneous TNF signal did not restore OC differentiation (figure $3 \mathrm{~A}$ ). In comparison, there was a TNF dose-dependent reduction in the development of mature multinucleated OCs (figure 3B). To demonstrate TNF specificity and exclude the possibility of cross-contamination, addition 
A
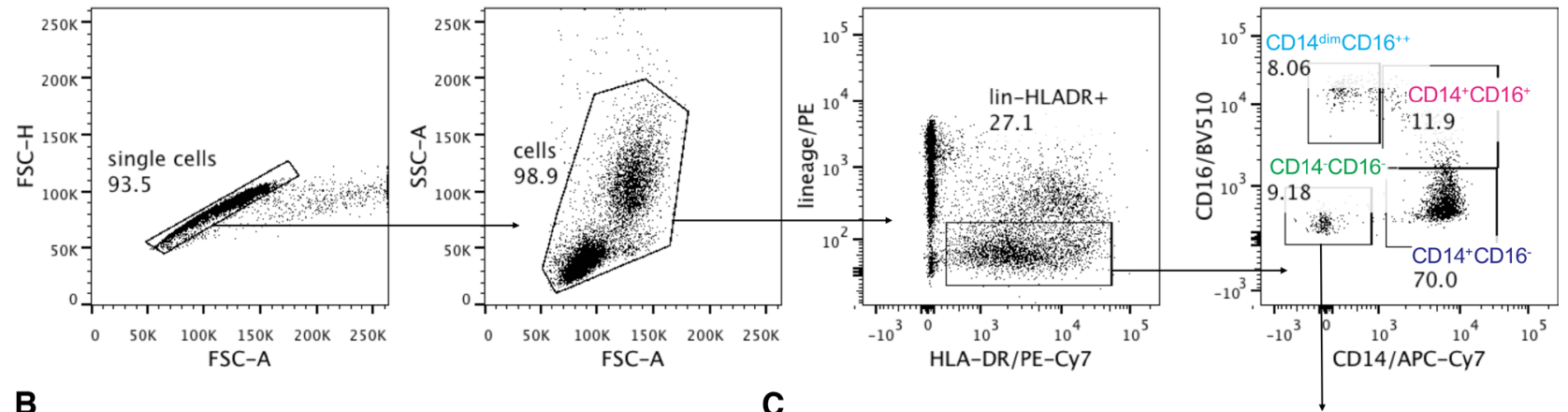

B

C
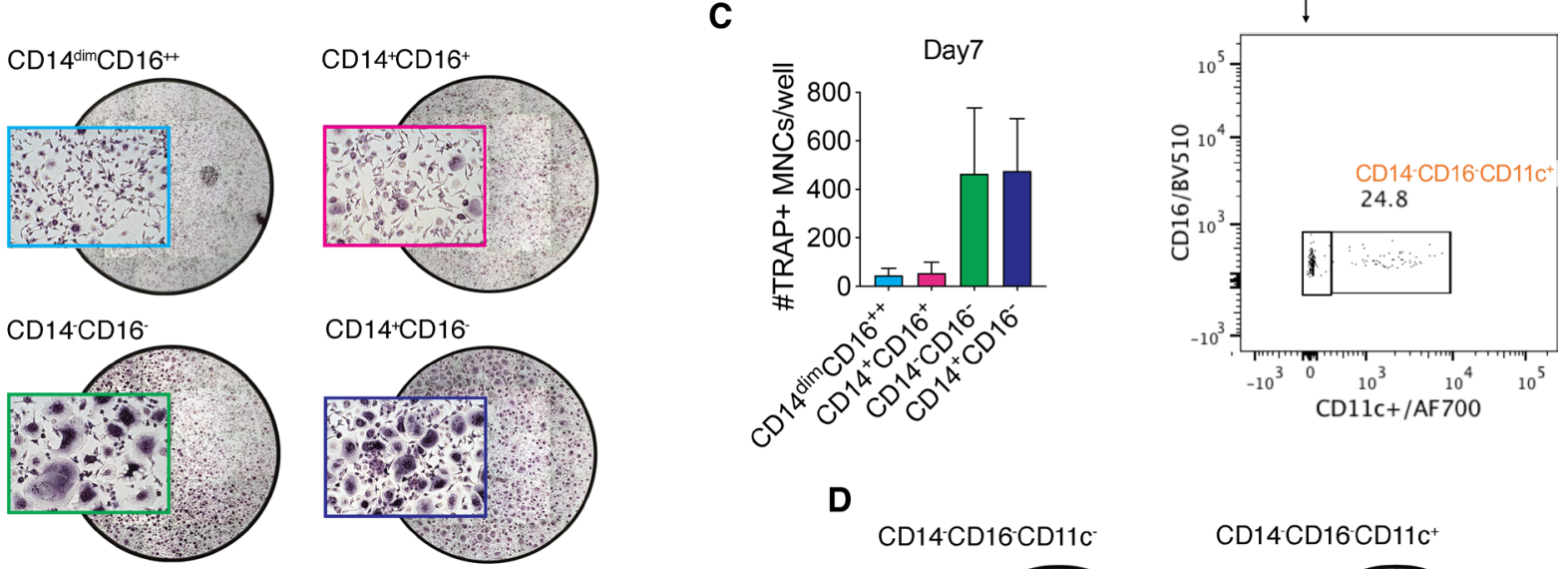

$\mathbf{E}$
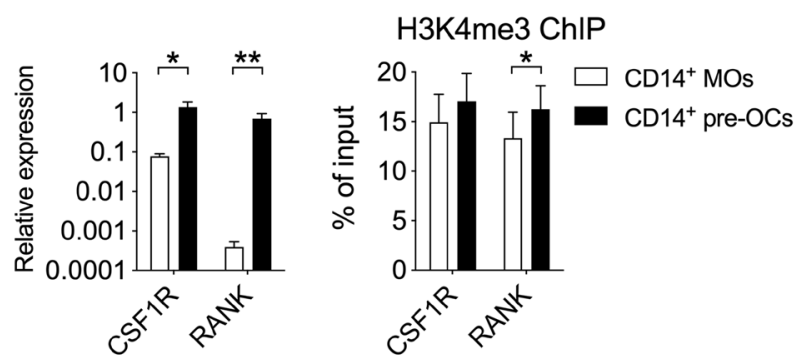

F
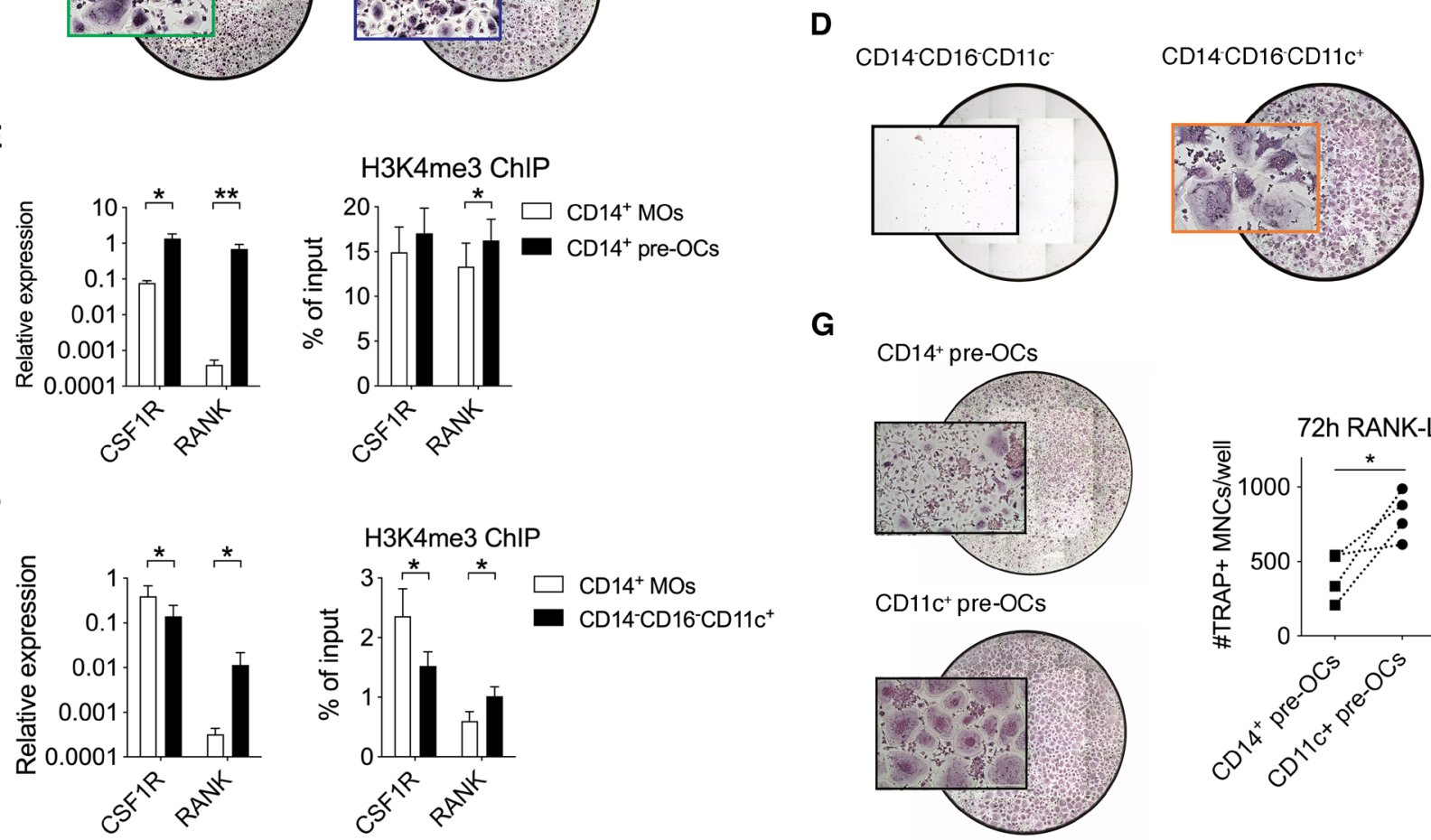

Figure 1 Identification and epigenetic state of osteoclast (OC) precursor populations in human blood. (A-D) Sorted peripheral blood mononuclear cells (PBMCs) were plated overnight with $25 \mathrm{ng} / \mathrm{mL}$ macrophage-colony stimulating factor (M-CSF) and subsequently $25 \mathrm{ng} / \mathrm{mL}$ receptor activator of nuclear factorkappa-B ligand (RANK-L) was added to differentiate cells into OCs. At day 7 cells were fixed and stained for TRAP. (A) Representative flow cytometric plots showing the gating strategy used to sort monocyte (MO) subsets and $C D 14^{-} C D 16^{-} C D 11 c^{+}$myeloid cells. Cells were pregated as single $\mathrm{Lin}^{-}\left(\mathrm{CD}_{19}{ }^{-} \mathrm{CD} 3^{-} \mathrm{CD} 15^{-} \mathrm{CD} 56^{-}\right) \mathrm{HLA}^{-D R^{+}}$. Numbers indicate percentage of parental subset. (B) Representative digital reconstructed wells at $4 \times$ (with a boxed $10 \times$ magnification) and (C) quantification of multinucleated (nuclei $\geq 3$ ) cells (MNCs) TRAP+ (purple) OC differentiated from $\mathrm{CD} 14^{\text {dim }} \mathrm{CD} 16^{++}, \mathrm{CD} 14^{+} \mathrm{CD} 16^{+}, \mathrm{CD} 14^{+} \mathrm{CD} 16^{-}$and $\mathrm{CD} 14^{-} \mathrm{CD} 16^{-}$subsets. (D) Representative digital images of TRAP stained wells at $4 \times$ with boxed 10x magnification images of $\mathrm{CD} 14^{-} \mathrm{CD} 16^{-} \mathrm{CD} 11 \mathrm{c}^{-}$and $\mathrm{CD} 14^{-} \mathrm{CD} 16^{-} \mathrm{CD} 11 \mathrm{c}^{+}$cells. $(\mathrm{E}-\mathrm{G}) \mathrm{CD} 14^{+} \mathrm{MOs}$ and $\mathrm{CD} 14^{-} \mathrm{CD} 16^{-} \mathrm{CD} 11 \mathrm{c}^{+}$precursors were magnetically enriched from PBMCs (purity $\geq 96 \%$ ) and incubated overnight with $25 \mathrm{ng} / \mathrm{mL}$ M-CSF to generate pre-OCs. (E-F) CSF1R and RANK mRNA expression (left hand side) and ChIP assay for H3K4me3 at promoter regions (right-hand side) of CSF1R and RANK genes in either (E) CD14 $4^{+}$MOs before and after $25 \mathrm{ng} / \mathrm{mL} \mathrm{M-CSF}$ overnight stimulation (CD14 $4^{+}$pre-OCs) and (F) in freshly isolated donor-matched CD14 ${ }^{+}$MOS and CD14 $4^{-}$CD16 ${ }^{-}$CD11 $c^{+}$myeloid cells. Bars show mean $\pm S D$. Data were analysed with two-way analysis of variance (ANOVA) for paired data and Sidak's multiple comparisons test or paired Wilcoxon t-test ( $n=3-4$ in $E$ and $n=6$ in $F$ ). ${ }^{*} p \leq 0.05 ;{ }^{* *} p \leq 0.01$. (G) Representative image of TRAP staining and quantification of TRAP+ MNCs/well of CD14 $4^{+}$pre-OCs and CD11 ${ }^{+}$pre-OCs after 72 hours of $25 \mathrm{ng} / \mathrm{mL}$ RANK-L. Dotted lines indicate donor-matched samples. Data were analysed with Mann-Whitney test $(n=4)$. ${ }^{*} p \leq 0.05$. 
A
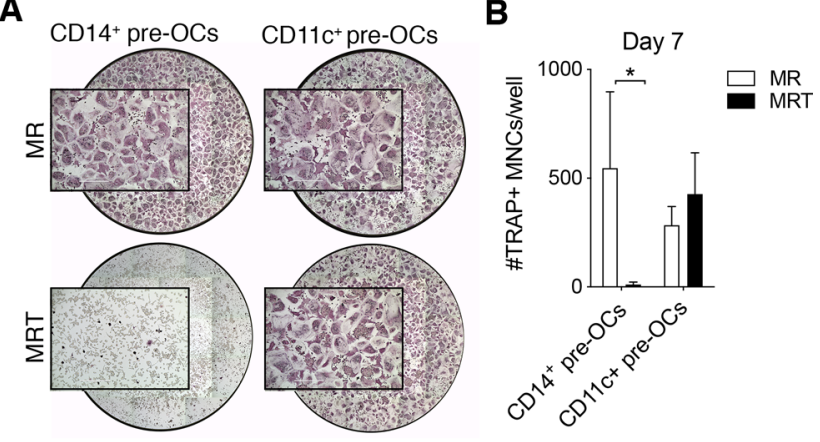

C

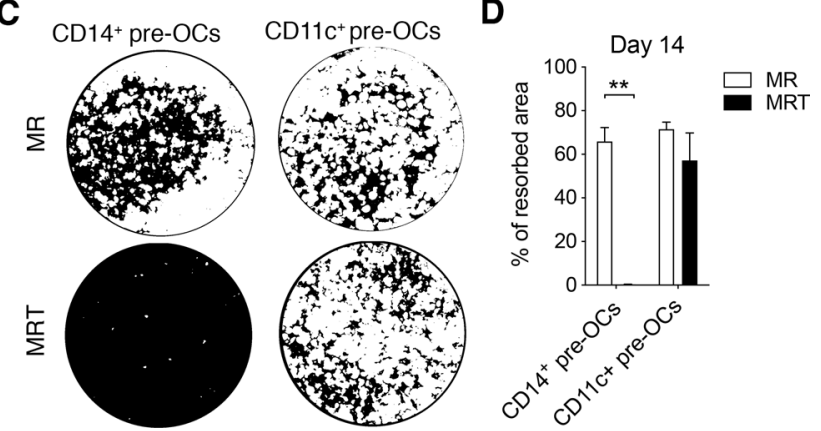

Figure 2 Tumour necrosis factor (TNF) over-rides receptor activator of nuclear factorkappa-B ligand (RANKL)-driven osteoclastogenesis of $\mathrm{CD}_{14}^{+}$pre-osteoclasts (OCs) but not CD11 $\mathrm{c}^{+}$pre-OCs. (A-B) Freshly isolated peripheral blood mononuclear cells (PBMCs) were stained for flow cytometry and $\mathrm{CD} 16^{-} \mathrm{CD} 14^{+}$monocytes (MOs) and $\mathrm{CD} 14^{-} \mathrm{CD} 16^{-} \mathrm{CD} 11 \mathrm{c}^{+}$precursors were sorted, incubated overnight with $25 \mathrm{ng} / \mathrm{mL}$ macrophage-colony stimulating factor to generate pre-OCs, and then differentiated into OCs for 7 days with $25 \mathrm{ng} / \mathrm{mL}$ RANK-L (MR) $\pm 10 \mathrm{ng} / \mathrm{mL}$ TNF (MRT). (A) Representative digital reconstructed TRAP stained wells at $4 \times$ with boxed $10 \times$ magnification and (B) quantification of numbers of TRAP+ multinucleated cells (MNCs) per well. Data were analysed with two-way analysis of variance (ANOVA) and Holm-Sidak's multiple comparisons test for paired data $(n=3)$. ${ }^{*} p \leq 0.05$. Error bars show mean $\pm S D$ of $n=3$. (C-D) CD14 ${ }^{+} \mathrm{MOs}$ and $\mathrm{CD} 14^{-} \mathrm{CD} 16^{-} \mathrm{CD} 11 \mathrm{C}^{+}$precursors were magnetically enriched, seeded onto mineral-coated wells, and differentiated into OCs for 14 days as in $(A, B)$. (C) Digital images of resorption pits (mineral substrate in black; resorption pits in white) and (D) \% of resorption. Statistical analysis was performed using two-way ANOVA and Sidak's multiple comparisons test for paired data. Error bars $=$ mean $\pm S D$ of $n=3$. ${ }^{*} p \leq 0.01$.

of the TNF inhibitor etanercept ${ }^{27}$ reversed osteoclastogenesis (online supplemental figure S3A,B).

To characterise the time-dependence of this effect of TNF, $\mathrm{CD}_{14}{ }^{+}$pre-OCs were stimulated with suboptimal levels of RANK-L that resulted in the appearance of mono-nucleated and bi-nucleated $\mathrm{TRAP}^{+}$cells after 72 hours stimulation. The addition of TNF at this 72 hours time-point did not inhibit osteoclastogenesis (online supplemental figure S4A,B) but rather caused an increase in OCs (online supplemental figure S4C), consistent with many previous studies. ${ }^{28}$ Therefore, the kinetics of exposure to TNF are critical for its effect on differentiation of CD14 ${ }^{+}$ pre-OCs into mature OCs; with precursors initially having to commit to the OC lineage before there is a positive synergy between RANK and TNF.

To investigate the molecular mechanism responsible for early TNF exposure-mediated inhibition observed in $\mathrm{CD}_{14}{ }^{+}$preOCs, we examined the epigenetic state of the RANK promoter and the resulting transcript and protein expression. On 4 hours
A

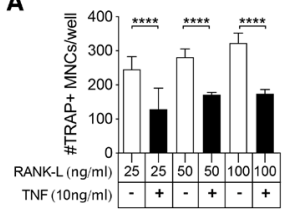

B

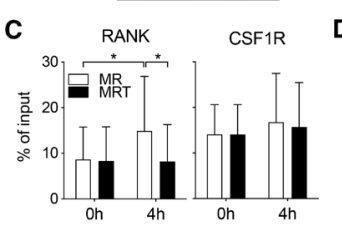

E
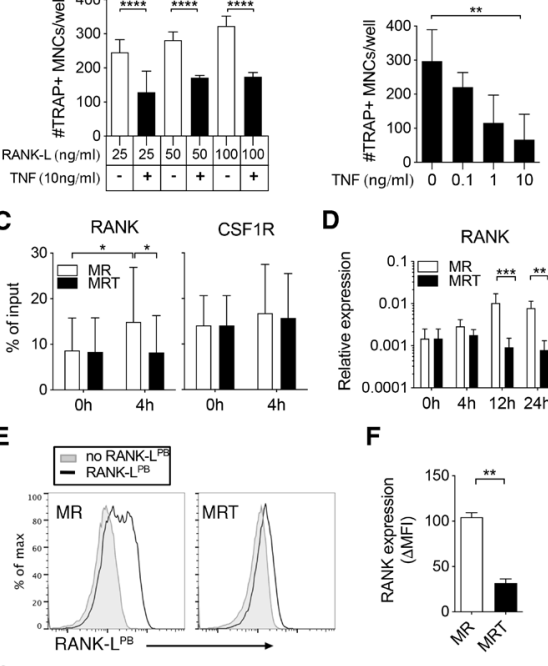

D

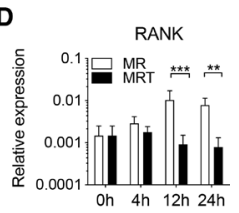

F

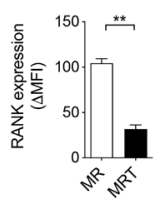

G

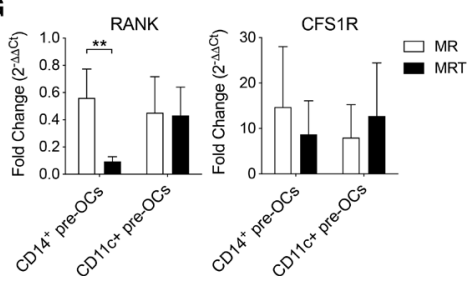

Figure 3 Tumour necrosis factor (TNF) mediates epigenetic modification of the receptor activator of nuclear factor kappa-B (RANK) promoter and controls RANK transcription and expression in CD14 ${ }^{+}$ pre-osteoclasts (OCs). (A-F) Enriched $\mathrm{CD} 14^{+}$monocytes (MOs) were incubated overnight with $25 \mathrm{ng} / \mathrm{mL}$ to generate $\mathrm{CD} 14^{+}$pre-OCs. OCs were differentiated in the presence of RANK-ligand (RANK-L) \pm TNF.

(A) Quantification of number of TRAP+ multinucleated cells (MNCs)/ well after 6 days of culture in increasing concentrations of RANK-L (25, 50 or $100 \mathrm{ng} / \mathrm{mL}) \pm 10 \mathrm{ng} / \mathrm{mL}$ TNF. Error bars show mean $\pm S D$ of $n=3$. Data were analysed with two-way analysis of variance (ANOVA) and Tukey's multiple comparisons test. ${ }^{* * *} p \leq 0.0001$. (B) Quantification of TRAP+ MNCs/well after 6 days of $25 \mathrm{ng} / \mathrm{mL}$ RANK-L \pm TNF at different concentrations $(0.1,1$ or $10 \mathrm{ng} / \mathrm{mL})$. Bars $=$ mean $\pm S D$ of $n=3$. Data were analysed with Friedman test with Dunn's multiple comparisons test, comparing to $0 \mathrm{ng} / \mathrm{mL}$ TNF. ${ }^{*} \mathrm{p} \leq 0.01$. (C-F) CD14 ${ }^{+}$pre-OCs were differentiated in the presence of $25 \mathrm{ng} / \mathrm{mL}$ macrophage-colony stimulating factor (M-CSF) $+25 \mathrm{ng} / \mathrm{mL}$ RANK-L (MR) or MR $+10 \mathrm{ng} /$ mL TNF (MRT). (C) ChIP assay for H3K4me3 at the RANK promoter (left-hand side) and at the CSF1R promoter (right-hand side) on CD14 ${ }^{+}$pre-OCs (0 hour) and after 4 hours MR or MRT stimulation. Bars show mean $\pm S D$ of $n=4$. Data were analysed with two-way ANOVA for paired data and Sidak's multiple comparisons test. * $p \leq 0.05$. (D) mRNA expression of RANK was evaluated at $0,4,12$, and 24 hours after cytokine addition on $\mathrm{CD} 14^{+}$pre-OCs. Data were analysed with two-way ANOVA and Dunnet's multiple comparisons test. ${ }^{* *} p \leq 0.01$; ${ }^{* * *} p<0.001 ; n=4$. (E) Representative histograms of uptake of fluorescent RANK-L (RANK-L ${ }^{\mathrm{PB}}$; black lines) after 72 hours of MR or MRT stimulation. Grey filled lines indicate unstained controls. (F) Graph shows quantification of RANK-L ${ }^{\mathrm{PB}}$ uptake; $\triangle \mathrm{MFI}$ was calculated by subtraction of the unstained background fluorescence. Statistical significance was assessed via one-way ANOVA and Holm-Sidak's multiple comparisons test. ${ }^{*} p \leq 0.01 ; n=3$. (G) CD14 ${ }^{+}$pre-OCs and CD11 $\mathrm{c}^{+}$pre-OCs were stimulated with MR or MRT for 4 hours. Graphs show RANK and CSF1R mRNA fold change, calculated by normalising to values at 0 hour prior stimulation (on pre-OCs after overnight M-CSF). Statistical significance was calculated using 2-way ANOVA for paired data and Sidak's multiple comparisons test. ${ }^{* *} p \leq 0.01{ }^{*} p \leq 0.05$. Error bars show mean $\pm S D$ of $n=5$. 
stimulation with RANK-L, CD14 ${ }^{+}$pre-OCs displayed enhanced H3K4me3 at the RANK promoter, with subsequent increased RANK transcript at 12 hours and 24 hours (figure $3 \mathrm{C}, \mathrm{D}$ ). The simultaneous addition of TNF with RANK-L suppressed this enhanced H3K4me3 and upregulation of transcript (figure 3C,D). This correlated with suppression of RANK expression at the cell surface (figure 3E,F). Notably, H3K4me3 levels at the CSF1R promoter and CSF1R transcripts were unaltered on RANK-L \pm TNF stimulation (figure $3 \mathrm{C}$ and online supplemental figure S5). As noted before, in contrast to $\mathrm{CD} 14^{+}$pre-OCs, CD $11 \mathrm{c}^{+}$ pre-OCs were not sensitive to the TNF inhibition (figure 2). To investigate the disconnect between the two cell types, we evaluated the transcriptional expression of RANK post-TNF treatment in donor-matched CD $14^{+}$pre-OCs and CD $11 c^{+}$pre-OCs. Simultaneous addition of TNF with RANK-L suppressed the level of RANK in $\mathrm{CD}_{14}{ }^{+}$pre-OCs but not in $\mathrm{CD} 11 \mathrm{c}^{+}$pre-OCs (figure 3G). Combined, these data suggest that TNF-mediated signalling in $\mathrm{CD} 14^{+}$-derived $\mathrm{OC}$ precursors, but not $\mathrm{CD} 14^{-} \mathrm{C}$ $\mathrm{D} 16^{-} \mathrm{CD} 11 \mathrm{c}^{+}$precursors, epigenetically modulates the RANK locus, resulting in loss of transcript and protein expression.

\section{TNF over-rides RANKL-driven osteoclastogenesis of CD14 ${ }^{+}$ circulating precursors via a TNFR1 and canonical NF-KB pathway}

RANK-L and TNF belong to the same TNF superfamily; stimulation of their respective receptors results in activation of NF- $\kappa \mathrm{B}$. However, TNF stimulation of TNFR1 and TNFR2 primarily leads to activation of the canonical and non-canonical NF- $\kappa \mathrm{B}$ pathways, respectively. ${ }^{29} 30$ RANK-L stimulation of RANK predominately leads to the activation of the non-canonical NF- $\kappa$ B pathway. ${ }^{31}$ TNFR1 and TNFR2 are expressed on both
A

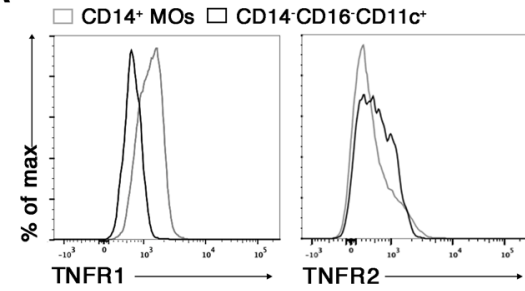

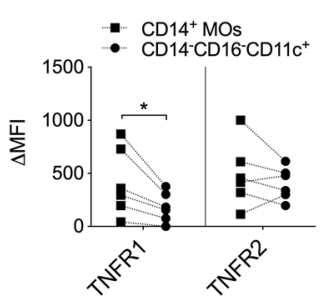

B
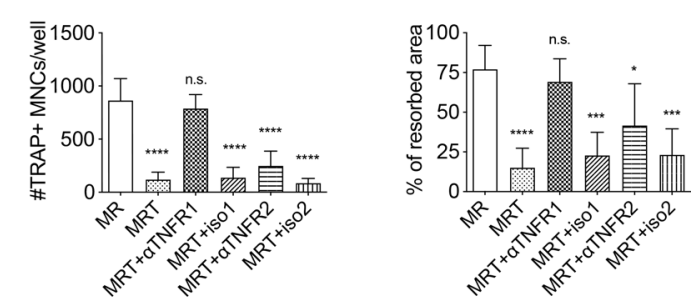

E
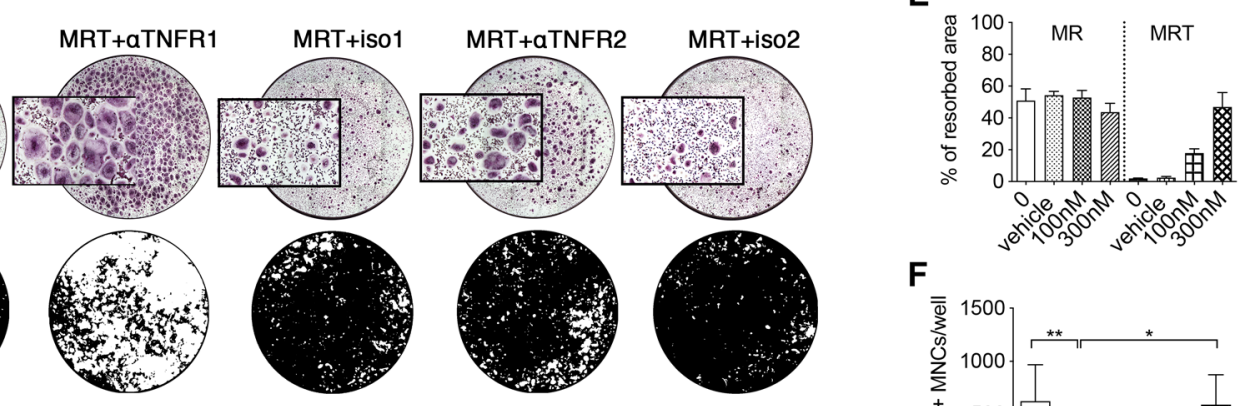

$\mathbf{F}$

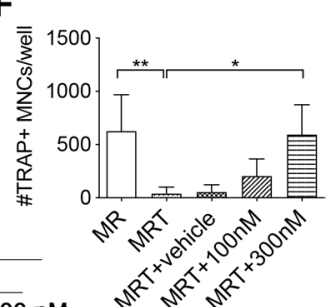
TPCA-1
D

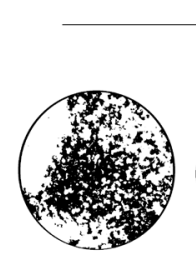

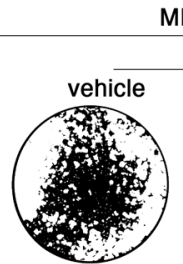

MR

TPCA-1

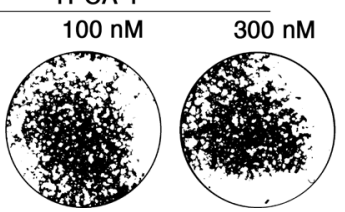

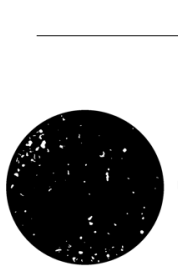

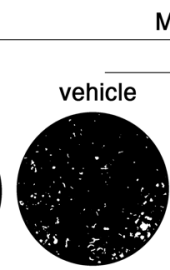

MRT

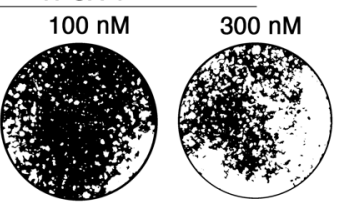

Figure 4 Tumour necrosis factor (TNF) over-rides receptor activator of nuclear factorkappa-B ligand (RANKL)-driven osteoclastogenesis of CD14 ${ }^{+}$ pre-osteoclasts (OCS) via a TNFR1 and canonical NF-kB pathway. (A) Freshly isolated peripheral blood mononuclear cells (PBMCs) were stained for flow cytometry. Representative histograms showing TNFR1 and TNFR2 expression on CD14 $4^{+}$monocytes (MOs) and CD14 $4^{-}$CD16 $6^{-}$CD11 $c^{+}$precursors and quantification of $\triangle$ mean fluorescence intensity (MFIs) (calculated by subtracting the MFI of the TNFR to the relative MFI of the isotype control). Cells were pre-gated on single $\mathrm{Lin}^{-}\left(\mathrm{CD}^{-} \mathrm{CD} 19^{-} \mathrm{CD} 15^{-} \mathrm{CD} 56^{-}\right) \mathrm{HLA}-\mathrm{DR} \mathrm{R}^{+}$. Dotted lines indicate donor-matched samples. Data were analysed with Wilcoxon matched-paired signed rank test $(n=6)$. ${ }^{*} p \leq 0.05$. (B-F) $C D 14^{+}$pre-OCs were differentiated in the presence of $25 \mathrm{ng} / \mathrm{mL}$ macrophagecolony stimulating factor $+25 \mathrm{ng} / \mathrm{mL}$ RANK-L (MR) or MR $+10 \mathrm{ng} / \mathrm{mL}$ TNF (MRT). (B) Quantification of numbers of TRAP+ MNCs/well (top graph) and $\%$ of resorbed area (bottom graph) calculated, respectively at day 7 and day 10 of MR or MRT cultures \pm antibody blocking TNFR1 or TNFR2 ( $\alpha$ TNFR1 and $\alpha$ TNFR2) or \pm the respective isotype controls (iso1 and iso2, respectively). Statistical significance was assessed with two-way analysis of variance (ANOVA) and Sidak's multiple comparisons test, comparing all data to MR. Error bars=mean $\pm S D$ of $n=3$. ${ }^{* * *} p<0.001,{ }^{* * * *} p<0.0001$. (C) Representative digital reconstructed wells of TRAP staining and 10x magnifications (in purple) at day 7 (top) and mineral-coated wells (mineral substrate in black; resorption pits in white) at day 10 (bottom) of CD14+-derived OC culture. (D) Representative digital images of resorption assay at day 10, (E) quantification of \% of resorbed area and (F) quantification of numbers of TRAP+ MNCs/well differentiated at day 7 with MR or MRT in the presence of an IKK- $\beta$ inhibitor at $100 \mathrm{nM}(\mathrm{MRT}+100 \mathrm{nM})$ or $300 \mathrm{nM}(\mathrm{MRT}+300 \mathrm{nM})$ or+vehicle control (MRT+V). (E) Mean $\pm S D$ of one representative experiment of $n=4$. Data in (F) were analysed with Friedman analysis of variance and Dunn's multiple comparisons test. ${ }^{*} p \leq 0.05 ;{ }^{* *} p \leq 0.01$. Error bars indicate mean $\pm S D$ of $n=3$. 
$\mathrm{CD}_{14}{ }^{+}$circulating $\mathrm{MOs}$ and $\mathrm{CD} 14^{-} \mathrm{CD} 16^{-} \mathrm{CD} 11 \mathrm{c}^{+}$myeloid cells (figure 4A).$^{32}$ However, the level of TNFR1 is significantly lower on $\mathrm{CD}_{14}^{-} \mathrm{CD} 16^{-} \mathrm{CD} 11 \mathrm{c}^{+}$precursors (figure 4A). To assess the role of TNFR1 and TNFR2 in the TNF-mediated inhibition of OC differentiation from CD14 ${ }^{+}$MOs, we utilised TNFR1specific and TNFR2-specific blocking antibodies. Blockade of TNFR1, but not TNFR2, mitigated the inhibitory effect of TNF on OC numbers and function (figure 4B,C). Given that TNFR1mediated signalling is through the canonical NF- $\kappa B$ pathway (via the I $\mathrm{B}$ B kinase (IKK) complex formed by IKK- $\alpha$, IKK- $\beta$ and NEMO), ${ }^{30}$ we used a selective IKK- $\beta$ inhibitor (TPCA-1) to specifically block this signalling cascade. Inhibition of IKK- $\beta$ significantly suppressed the ability of TNF to inhibit OC differentiation and activation (figure 4D-F). Importantly, TPCA-1 did not affect RANK-L-induced osteoclastogenesis or their resorptive capacity (figure $4 \mathrm{D}, \mathrm{E}$ ), as this is primarily driven by noncanonical NF- $\kappa$ B signalling. ${ }^{33-35}$ TNFR1-mediated signals have also been associated with initiation of caspase cascades and subsequent apoptosis. TNF stimulation of $\mathrm{CD} 14^{+}$pre-OCs resulted in decreased caspase activation and no change in apoptosis levels (online supplemental figure S6). Interestingly, RANK-L-mediated differentiation of $\mathrm{CD}_{14}{ }^{+}$pre-OCs for 72 hours resulted in upregulation of TNFR2 (online supplemental figure S7A,B). This corresponded with TNFR2-dependent TNF-mediated enhancement of OC differentiation in these precommitted OC precursors (online supplemental figure S7C,D). Taken together, our data reveal a fundamental dual role of TNF in enhancing or blocking OC differentiation. Early exposure to concomitant RANK-L and TNF activates the canonical NF- $\kappa$ B pathway via TNFR1 and halts osteoclastogenesis; in contrast, later TNF addition on precommitted pre-OCs aids RANK-L and osteoclastogenesis via TNFR2 and non-canonical NF- $\kappa B$ signalling. This may also partly explain why circulating $\mathrm{CD} 14^{-} \mathrm{CD} 16^{-} \mathrm{CD} 11 \mathrm{c}^{+}$ precursors are unresponsive to TNF-mediated inhibition, given their lower levels of TNFR1 (figure 4A).

\section{Patients with RA have a perturbed myeloid compartment and} TNF does not negatively regulate $\mathrm{OC}$ differentiation

Cell in the myeloid compartment and TNF play key roles in RA pathology. Analysis of circulating $\mathrm{CD} 14^{+} \mathrm{MOs}$ and $\mathrm{CD} 14^{-} \mathrm{C}-$ $\mathrm{D} 16^{-} \mathrm{CD} 11 \mathrm{c}^{+}$precursors in our RA cohort showed that while the abundance of CD $14^{+}$MOs was not affected in RA, CD $14^{-} \mathrm{C}$ D $16^{-} \mathrm{CD} 11 \mathrm{c}^{+}$precursors were significantly reduced (figure $5 \mathrm{~A}$ ).
A

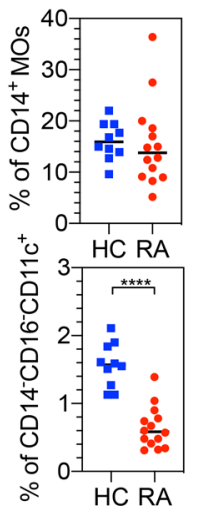

B

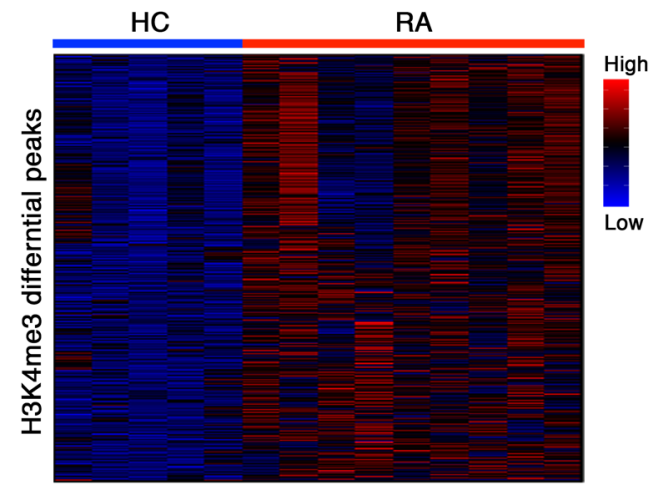

E

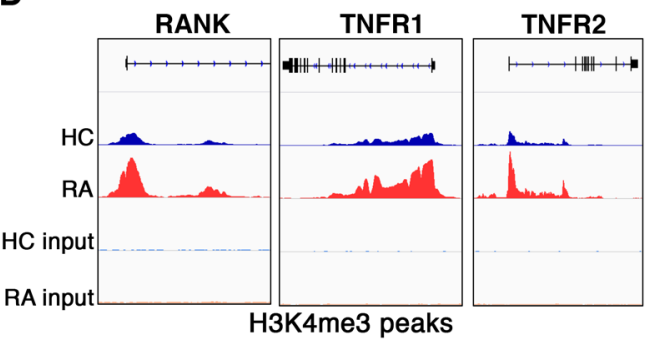

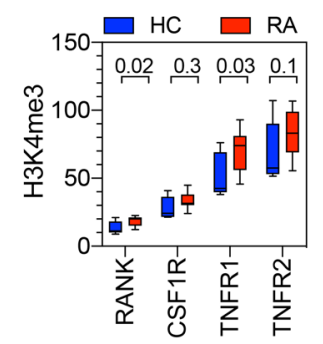

C

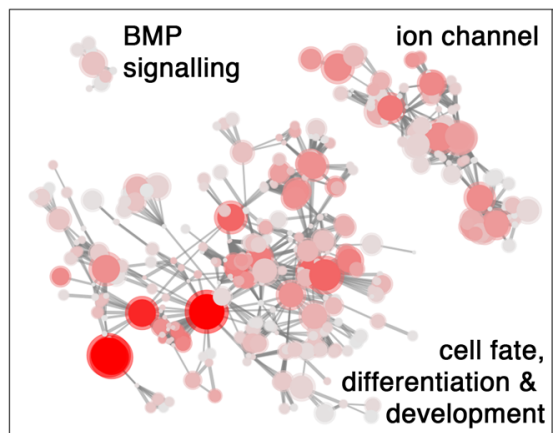

$\mathbf{F}$

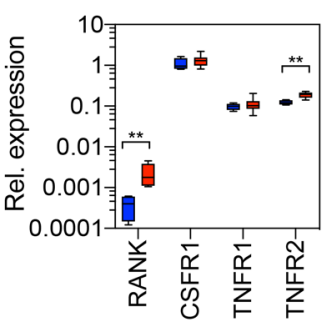

Figure 5 Patients with rheumatoid arthritis (RA) have epigenetically perturbed CD14 ${ }^{+}$monocytes with increased receptor activator of nuclear factor kappa-B (RANK) expression. (A) Freshly isolated peripheral blood mononuclear cells (PBMCs) from healthy controls (HC) and RA were stained for flow cytometry and percentages of CD14 ${ }^{+} \mathrm{MOs}$ and $\mathrm{CD} 14^{-} \mathrm{CD} 16^{-} \mathrm{CD} 11 \mathrm{c}^{+}$precursors in PBMCs were calculated. Statistical significance was calculated using unpaired t-test $(n=10 \mathrm{HC}$ and $n=14 \mathrm{RA})$. ${ }^{* * * *} \mathrm{p} \leq 0.0001$. (B) Diffbind normalised peak intensity heatmap highlighting the size and consistency of differences between HC and RA. Samples are given by column and the 6763 significantly differential peaks (<5\% FDR) by row. Colour intensity indicates row scaled (z-score) peak intensity with blue as low and red as high. Rows have been hierarchically clustered using Spearman distances. (C) Network plot of the enriched $(p<0.0001)$ Gene Ontologies for the 6763 significantly differential peaks (FDR $<5 \%$ ). Nodes denote Gene Ontologies and edges join nodes where $>50 \%$ significant peak containing genes are shared. Node colour intensity represents enrichment (-log10p) and node size the number of significant peaks containing genes. Representative names for node clusters are given. (D) Genome Browser traces of the RANK, TNFR1 and TNFR2 H3K4me3 promoter peaks. (E) Input normalised peak intensity boxplots for the RANK, TNFR1 and TNFR2 promoter peaks (top) and relative mRNA expression measured on freshly isolated CD14 monocytes (MOs) from HC and RA (bottom). Unadjusted diffbind $p$ values are given in the top graph. Two-way analysis of variance (ANOVA) and Sidak's multiple comparisons test was used for the analysis in the bottom graph. Graph shows box and whiskers with min to max of $n=4$ for $H C$ and $n=11$ for RA. ${ }^{*} p \leq 0.05 ;{ }^{*} p \leq 0.01$. (F) Freshly isolated PBMCs from HC and RA were stained for flow cytometry to evaluate TNFR1 and TNFR2 expression. Box and whiskers show TNFR1 and TNFR2 expression on CD14 ${ }^{+}$MOs in $\triangle$ mean fluorescence intensity (MFIs) for $n=13$ each group. Error bars shows min to max variation. 
This is consistent with previous studies showing reduced mDCs in both RA bloodstream and inflamed synovium. ${ }^{36}$ Whether this is due to their rapid recruitment and differentiation in situ or to their minor contribution to bone erosion in RA pathology is not known. However, recent independent studies both in the blood and the synovium have interrogated the molecular signature of both $\mathrm{CD} 14^{+}$MOs and CD1C pre-DC (which are the closest subset to our CD11c ${ }^{+}$myeloid precursors) in RA. ${ }^{37}$ Analysis of this publicly available data revealed a high transcriptional correlation between blood and synovial CD1C cells (online supplemental figure S8A), indicating a common cell lineage origin. Notably, among the most differentially expressed gene, RANK was dramatically upregulated in the CD1C synovial counterpart, compared with circulating cells (online supplemental figure $\mathrm{S} 8 \mathrm{~B}$ ). These data taken together suggest that CD $11 \mathrm{c}^{+}$ (or CD1C cells) are present in the inflamed synovium and have the molecular potential to differentiate into OC; although their contribution to RA bone erosion remains elusive.

In contrast, although the abundance of circulating MOs was unaffected in RA, prior studies have shown that their transcriptional profile is different from non-inflammatory controls. ${ }^{39} \mathrm{We}$ therefore hypothesised, having shown that the epigenetic status of $\mathrm{CD} 14^{+}$MOs controls the inhibitory TNF effect, that RA blood CD $14^{+}$MOs may exhibit a distinct epigenetic state. To gain further insight into this dysregulation, genome-wide $\mathrm{H} 3 \mathrm{~K} 4 \mathrm{me} 3$ histone modification was investigated using ChIPseq. Comparison between patients with biological naïve RA with moderate to severe disease $(\mathrm{DAS} 28=4.44 \pm 0.9)$ and healthy control CD14 ${ }^{+}$ MOs, identified 6764 significantly differential peaks (adjusted $\mathrm{p}>0.05$ ) (figure 5B). Pathway enrichment and network analysis revealed that these differential peaks of RA MOs were primary associated with cell differentiation and development pathways (figure 5C and online supplemental dataset 1).

Based on the observed changes in RANK, CSF1R, TNFR1 and TNFR2 in healthy MOs, a focused analysis of the ChIPseq data showed that there was a significant increase of $\mathrm{H} 3 \mathrm{~K} 4 \mathrm{me} 3$ in RA CD14 ${ }^{+}$MOs at the RANK and TNFR1 loci but not TNFR2 and CSF1R (figure 5D,E). This corresponded with an increased level of RANK transcript but not TNFR1 (figure 5E). However, increased TNFR2 transcript was detected in RA CD14 ${ }^{+}$MOs (figure 5E), although this did not correspond to a significant increase in cell surface expression (figure 5F).

Given the observed altered epigenetic landscape in RA MOs and the strong evidence that TNF drives joint destruction in RA, we hypothesised that the homoeostatic effect of TNF on circulating myeloid cells would be perturbed in RA and could thus promote OC-mediated erosive pathology. To assess the impact of this on responsiveness to TNF, CD $14^{+}$pre-OCs from RA and healthy controls were differentiated in the presence of RANKL \pm TNF. While TNF consistently inhibited osteoclastogenesis in healthy controls, we observed a significant decrease in the capacity of TNF to inhibit osteoclastogenesis in patients with RA, with a certain degree of variance (figure $6 \mathrm{~A}$ ). In particular, $44 \%$ manifest TNF-mediated inhibition (responders), whereas in 56\% of patients TNF was unable to inhibit osteoclastogenesis (nonresponders; figure 6A,B). Remarkably, TNF had an enhancing pro-osteoclastogenic effect in $45 \%$ of the non-responder group. To further investigate the heterogeneity in the patients with RA, ChIPseq data of those patients that showed TNF-mediated inhibition (responders) and those that did not (non-responders) were compared. This analysis revealed that there were 4172 significantly differential peaks (figure 6C). Pathway enrichment showed that abundant peaks in RA MOs of the non-responder group were associated with transmembrane receptor protein kinase pathways and DNA-binding transcription repressor activity pathways (figure 6D and online supplemental dataset 2). Among the transmembrane receptor protein kinase pathways, CSF1R was found to be lower in the non-responders compared with the responders. STRING analysis of the identified transmembrane receptor protein kinase pathway associated genes also provided a link between CSF1R and NRP1 (figure 6E). Interestingly, NRP1 is known to act as a coreceptor for vascular endothelial growth factor (VEGF)- $\mathrm{R}^{40}$ in $\mathrm{MOs} /$ macrophage, and VEGFR expression and VEGF-mediated signalling has been associated with MO differentiation into OCs. ${ }^{4142}$ Evaluation of RA patient serum revealed that high levels of VEGF correlate with response to TNF (figure 6F). Combined, these data suggest that in a proportion of patients with RA the high levels of VEGF correlate with a perturbation in the myeloid compartment, such that TNF homoeostatic control is diminished, thereby enhancing the potential for maturation of OCs derived from the circulating MO pool when they enter the joint.

\section{DISCUSSION}

Our data reveal an unexpected role for TNF in the control of cell fate decisions in the myeloid compartment that regulates OC development and subsequent activation. In homoeostatic conditions, TNF can directly over-ride OC differentiation signals to which circulating myeloid precursors would otherwise respond. Furthermore, we have identified a specific human $\mathrm{Lin}^{-} \mathrm{HLA}^{-} \mathrm{DR}^{+} \mathrm{CD} 14^{-} \mathrm{CD} 16^{-} \mathrm{CD} 11 \mathrm{c}^{+}$precursor population that preferentially differentiates down the OC lineage, and that, based on its epigenetic state, is unresponsive to homoeostatic regulation imparted by TNF. In RA, a proportion of patients with moderate/severe disease activity exhibit failure of this regulatory role of TNF with some patients even exhibiting accelerated osteoclastogenesis on TNF exposure at this very early time point in the precursor differentiation pathway. This perturbed response is due to an altered MO epigenetic landscape. Taken together, our findings provide a novel, previously unrecognised hierarchy between TNF cytokine family members regulating cell fate decisions in both health and disease, which is mediated via the epigenetic set-point of circulating precursors defining their capacity to respond to cytokine combinations in the local milieu.

Our finding that homoeostatic TNF can control MO, but not other myeloid precursor differentiation in osteoclastogenic rich environments defines a paradigm in which priming of cells within the circulating myeloid compartment creates either a permissive or non-permissive epigenetic state that allows cells to differentiate down the most appropriate lineage. It is however, currently unclear how this epigenetic state is achieved in circulating MOs or how TNF drives additional changes, and thus the role of specific histone methyltransferase and/or demethylases should be evaluated in future studies. ${ }^{43}$ Previous studies have demonstrated that $\mathrm{CD} 14^{+} \mathrm{MO}$-derived immature DC-like cells have the ability to transdifferentiate into OCs more efficiently than CD14+ ${ }^{+}$MO progenitors. ${ }^{19}{ }^{44}$ Note however, that circulating pre-DCs are the only cell subset capable of generating classical DCs while CD $14^{+} \mathrm{MO}$ can only generate DC-like cells. $^{7}$ Our findings provide the first evidence that circulating human $\mathrm{Lin}^{-} \mathrm{HLA}^{-} \mathrm{DR}{ }^{+} \mathrm{CD} 14^{-} \mathrm{CD} 16^{-} \mathrm{CD} 11 \mathrm{c}^{+}$, which can also phenotypically be associated with the pre-DC population, can differentiate down the OC lineage. Whether $\mathrm{Lin}^{-} \mathrm{HLA}^{-} \mathrm{DR}^{+} \mathrm{C}$ D $14^{-} \mathrm{CD} 16^{-} \mathrm{CD} 11 \mathrm{c}^{+} /$pre-DCs are the missing OC precursor in humans remains to be conclusively determined.

Based on this work, we suggest that in a normal selfresolving inflammatory event (which can include sterile/acute 
A

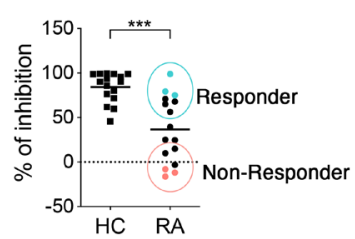

D

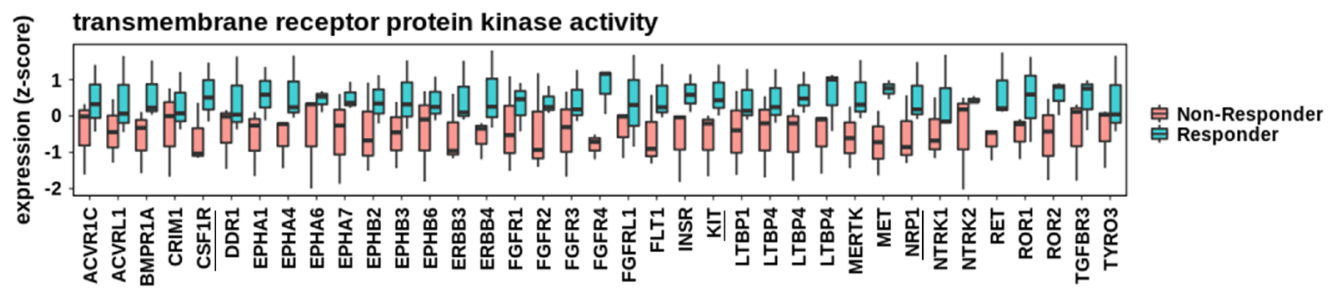

E

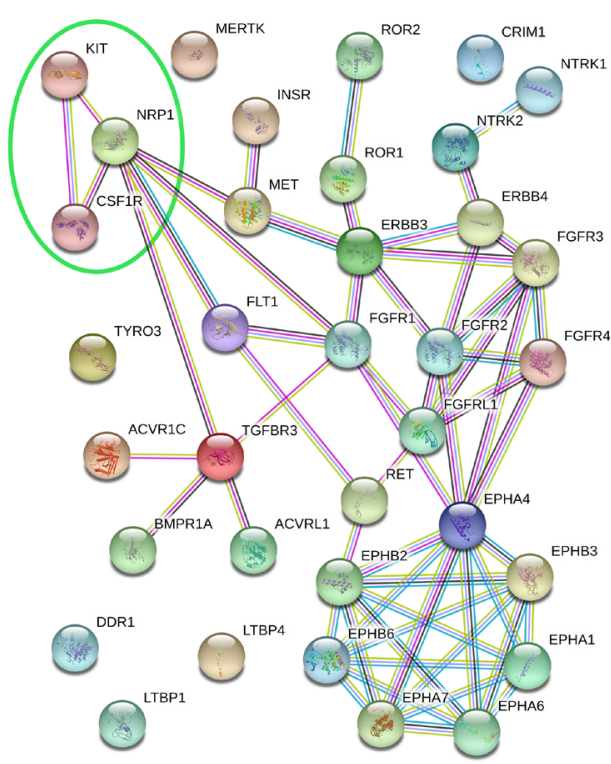

B

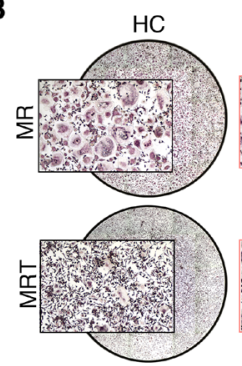

RA-Non-Responder

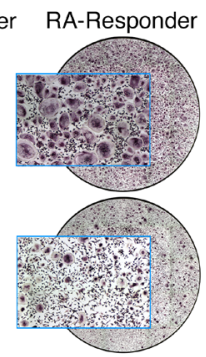

C

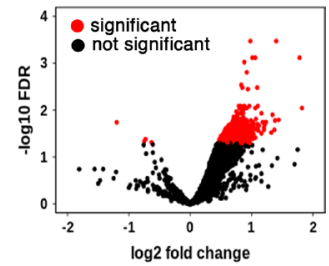

\section{F}
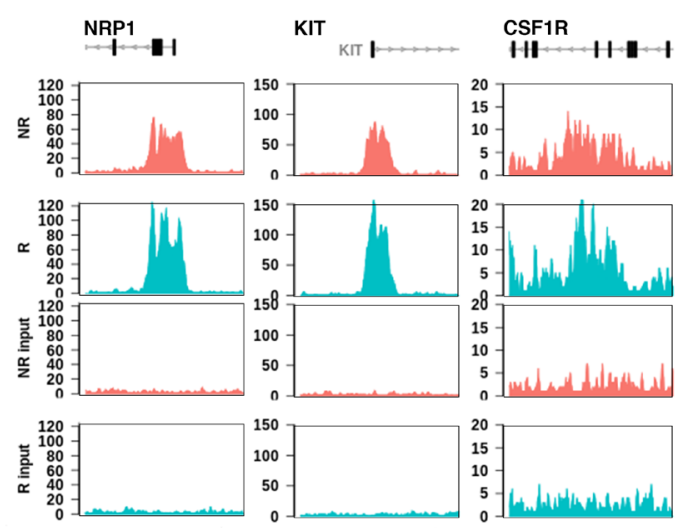

G

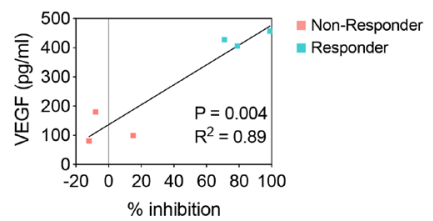

Figure 6 Tumour necrosis factor (TNF) does not inhibit CD14 $4^{+}$-derived osteoclast (OC) differentiation in a portion of patients with rheumatoid arthritis (RA). (A-B) CD14 $4^{+}$pre-OCs were differentiated for 7 days into OCs in the presence of $25 \mathrm{ng} / \mathrm{mL}$ macrophage-colony stimulating factor (MCSF) and receptor activator of nuclear factorkappa-B ligand (RANK-L) (MR) $\pm 10 \mathrm{ng} / \mathrm{mL}$ TNF (MRT). (A) Percentage of inhibition of OC differentiation was calculated as 100-[(100x\#OCs$\left.\left.{ }_{(\mathrm{MRT})}\right) / \# 0 \mathrm{Cs}_{(\mathrm{MRR})}\right]$ in patients with healthy controls $(\mathrm{HC})$ and RA. Light red dots indicate non-responder group and light blue dots the responder using in subsequent ChIP analysis. Data were analysed with Mann Whitney test $(n=16)$. ${ }^{*} p \leq 0.01$. (B) Representative reconstructed wells and 10x magnifications of TRAP staining of one representative HC, one RA non-responder and one RA responder, in MR and MRT conditions. OCs=TRAP+ multinucleated cells, MR=M-CSF+RANKL, MRT=M-CSF+RANK-L+TNF. (C) Volcano plot for RA responders versus nonresponders across the 65717 consensus peaks. Significantly differential peaks ( $<5 \% \mathrm{FDR})$ are highlighted in red. Positive fold changes denote greater peak intensity in RA responders. (D) Boxplot of the 35 significantly differential peaks ( $<5 \% \mathrm{FDR})$ between RA non-responders and RA responders that are associated with the top enriched $(p<0.0001)$ gene ontology transmembrane receptor protein kinase activity. Individual peaks (and the gene they are associated with) are given on the $\mathrm{x}$-axis and the Diffbind normalised peak intensity (per peak z-score) is given on the $y$-axis. Separate boxes are provided for non-responder samples $(n=3)$ and responder samples $(n=3)$. (E) STRING network plot of the genes in the transmembrane receptor protein kinase activity gene ontology. Nodes represent proteins and edges joining nodes represent protein-protein associations (known interactions; blue — curated data, pink — experimentally determined. Predicted interactions; green — gene neighbours. Other interaction; black—coexpression). Genes of interest are circled in green. (F) Correlation analysis between \% of inhibition of $\mathrm{OC}$ differentiation and serum vascular endothelial growth factor (VEGF) concentration.

inflammation), Lin $^{-} \mathrm{HLA}^{-} \mathrm{DR}^{+} \mathrm{CD} 14^{-} \mathrm{CD} 16^{-} \mathrm{CD} 11 \mathrm{c}^{+}$cells recruited to bone will still respond to the cytokine rich local environment by differentiating down the OC lineage and thus help maintain skeletal health. In contrast, circulating $\mathrm{CD} 14^{+}$ MOs are in a non-permissive state and are inhibited from contributing to the OC pool. We recognise the limitations of our study; in that we have used in vitro methods to evaluate cell fate decisions within the myeloid compartment. Evidence to further support this theory would require human in vivo/ ex vivo cell fate mapping studies to determine which precursors $\left(\mathrm{Lin}^{-} \mathrm{HLA}^{-} \mathrm{DR}^{+} \mathrm{CD} 14^{-} \mathrm{CD} 16^{-} \mathrm{CD} 11 \mathrm{c}^{+}\right.$or $\mathrm{CD} 14^{+} \mathrm{MOs}$ ) contribute to the bone-associated OC pool. Unfortunately, these assays are not currently possible. Further studies will need to define a way of identifying $\mathrm{Lin}^{-} \mathrm{HLA}^{-} \mathrm{DR}^{+} \mathrm{CD} 14^{-} \mathrm{C}$ D16 ${ }^{-} \mathrm{CD} 11 \mathrm{c}^{+}$-versus MO-derived OCs in situ to better understand this alternative route to mature OCs. Moreover, they 
should also investigate the global molecular and epigenetic signature of $\mathrm{Lin}^{-} \mathrm{HLA}^{-} \mathrm{DR}{ }^{+} \mathrm{CD} 14^{-} \mathrm{CD} 16^{-} \mathrm{CD} 11 \mathrm{c}^{+}$and $\mathrm{CD} 14^{+}$ precursors cells, and their respective mature OCs, to ultimately identify the specific precursor cells and molecular mechanisms involved in inflammatory joint destruction.

Anti-TNF therapy is one of the gold standard treatments for multiple inflammatory-mediated diseases including RA. It is paradoxical however, given that TNF inhibitors are known to be antierosive, ${ }^{45}$ that we show an antierosive effect for TNF itself via a homoeostatic pathway in health. Crucially, we do show that in a proportion of patients with RA with have higher levels of VEGF, there is a failure in this homoeostatic pathway. Leading us to hypothesise that such failure may represent a route MO preconditioning and subsequent accelerated erosion in a subset of patients. Characterising the nature of such a failure may offer future therapeutic opportunities. For instance, determining how to re-engage this regulatory pathway may lead to new antierosive therapeutics that have the ability to re-sensitise some patients with RA to the regulatory element of TNF biology. This could also have the added value of reducing the capacity of TNF, produced for example during RA synovitis, to sensitise early precursors down the OC pathway. Finally, the newly identified $\mathrm{Lin}^{-} \mathrm{HLA}^{-} \mathrm{DR}^{+} \mathrm{CD} 14^{-} \mathrm{CD} 16^{-} \mathrm{CD} 11 \mathrm{c}^{+}$precursor route to mature OCs represents an unexplored independent mechanism to mature OCs and potentially erosive progression in RA. A detailed understanding of this new pathway could reveal an as yet untargeted pathway in the disease context. In summary, these data support further evaluation of these pathways in RA and other diseases associated with bone pathology to discover their utility as alternative therapeutic strategies to abrogate erosive progression.

Twitter Stefan Siebert @StefanSiebert1 and Carl S Goodyear @carl_goodyear

Acknowledgements We thank the patients with RA and healthy donors who participated in this study.

Contributors CA, IM and CSG conceived and designed the concepts, experiments, data analysis and overall research. IM and CSG directed the research. CA, FS, SC, performed experiments and data analysis. JC performed the bioinformatic analyses. SSood helped with sample processing and technical troubleshooting. JR and SSiebert collected clinical samples and provided assistance in clinical interpretation. CA, IM and CSG wrote the manuscript with the input of the other authors.

Funding The work was supported by European Commission Seventh Framework Programme and Marie Curie Actions (project Osteoimmune; FP7-PEO- PLE2011-ITN-289150) with additional support by ARUK Centre of Excellence for the Pathogenesis of Rheumatoid Arthritis (RACE/\#20298). FS was supported by an ARTICULUM Fellowship.

Competing interests None declared.

Patient consent for publication Not required.

Provenance and peer review Not commissioned; externally peer reviewed.

Data availability statement Data are available in a public, open access repository. Data and materials availability: ChIP-seq datasets were deposited in Gene Expression Omnibus (GEO) with the accession number ID GSE15291 and token irctaigmjlmxtkj (https://www.ncbi.nlm.nih.gov/geo/query/acc.cgi?acc=GSE152912)

Supplemental material This content has been supplied by the author(s). It has not been vetted by BMJ Publishing Group Limited (BMJ) and may not have been peer-reviewed. Any opinions or recommendations discussed are solely those of the author(s) and are not endorsed by BMJ. BMJ disclaims all liability and responsibility arising from any reliance placed on the content. Where the content includes any translated material, BMJ does not warrant the accuracy and reliability of the translations (including but not limited to local regulations, clinical guidelines, terminology, drug names and drug dosages), and is not responsible for any error and/or omissions arising from translation and adaptation or otherwise.

Open access This is an open access article distributed in accordance with the Creative Commons Attribution 4.0 Unported (CC BY 4.0) license, which permits others to copy, redistribute, remix, transform and build upon this work for any purpose, provided the original work is properly cited, a link to the licence is given, and indication of whether changes were made. See: https://creativecommons.org/ licenses/by/4.0/.

\section{ORCID iDs}

Cecilia Ansalone http://orcid.org/0000-0001-8683-1718

Jamie Robertson http://orcid.org/0000-0003-2575-9331

Carl S Goodyear http://orcid.org/0000-0001-5926-5941

\section{REFERENCES}

1 Jacome-Galarza CE, Percin Gl, Muller JT, et al. Developmental origin, functional maintenance and genetic rescue of osteoclasts. Nature 2019;568:541-5.

2 Boyle WJ, Simonet WS, Lacey DL. Osteoclast differentiation and activation. Nature 2003:423:337-42.

3 Li J, Sarosi I, Yan XQ, et al. Rank is the intrinsic hematopoietic cell surface receptor that controls osteoclastogenesis and regulation of bone mass and calcium metabolism. Proc Natl Acad Sci U S A 2000;97:1566-71.

4 Jacome-Galarza CE, Lee S-K, Lorenzo JA, et al. Identification, characterization, and isolation of a common progenitor for osteoclasts, macrophages, and dendritic cells from murine bone marrow and periphery. J Bone Miner Res 2013;28:1203-13.

5 Rivollier A, Mazzorana M, Tebib J, et al. Immature dendritic cell transdifferentiation into osteoclasts: a novel pathway sustained by the rheumatoid arthritis microenvironment. Blood 2004;104:4029-37.

6 Guilliams M, Ginhoux F, Jakubzick C, et al. Dendritic cells, monocytes and macrophages: a unified nomenclature based on ontogeny. Nat Rev Immunol 2014; 14:571-8.

7 Villani A-C, Satija R, Reynolds G, et al. Single-cell RNA-seq reveals new types of human blood dendritic cells, monocytes, and progenitors. Science 2017;356. doi:10.1126/science.aah4573. [Epub ahead of print: 21 Apr 2017].

8 Charles JF, Hsu L-Y, Niemi EC, et al. Inflammatory arthritis increases mouse osteoclast precursors with myeloid suppressor function. J Clin Invest 2012;122:4592-605.

9 Komine M, Kukita A, Kukita T, et al. Tumor necrosis factor-alpha cooperates with receptor activator of nuclear factor kappaB ligand in generation of osteoclasts in stromal cell-depleted rat bone marrow cell culture. Bone 2001:28:474-83.

10 Lam J, Takeshita S, Barker JE, et al. TNF- $\alpha$ induces osteoclastogenesis by direct stimulation of macrophages exposed to permissive levels of RANK ligand. J Clin Invest 2000;106:1481-8

11 Zhang YH, Heulsmann A, Tondravi MM, et al. Tumor necrosis factor-alpha (TNF) stimulates RANKL-induced osteoclastogenesis via coupling of TNF type 1 receptor and RANK signaling pathways. J Biol Chem 2001:276:563-8.

12 Kalliolias GD, Ivashkiv LB. TNF biology, pathogenic mechanisms and emerging therapeutic strategies. Nat Rev Rheumatol 2016:12:49-62.

13 Keffer J, Probert L, Cazlaris H, et al. Transgenic mice expressing human tumour necrosis factor: a predictive genetic model of arthritis. Embo J 1991;10:4025-31.

14 Manara M, Sinigaglia L. Bone and TNF in rheumatoid arthritis: clinical implications. RMD Open 2015;1:e000065.

15 Shi C, Pamer EG. Monocyte recruitment during infection and inflammation. Nat Rev Immunol 2011;11:762-74.

16 Massey HM, Flanagan AM. Human osteoclasts derive from CD14-positive monocytes. Br J Haematol 1999;106:167-70

17 Komano Y, Nanki T, Hayashida K, et al. Identification of a human peripheral blood monocyte subset that differentiates into osteoclasts. Arthritis Res Ther 2006;8:R152

18 Tinkler SM, Linder JE, Williams DM, et al. Formation of osteoclasts from blood monocytes during 1 alpha-OH Vit D-stimulated bone resorption in mice. J Anat 1981:133:389-96.

19 Gallois A, Lachuer J, Yvert G, et al. Genome-wide expression analyses establish dendritic cells as a new osteoclast precursor able to generate bone-resorbing cells more efficiently than monocytes. J Bone Miner Res 2010;25:661-72.

20 MacLellan LM, Montgomery J, Sugiyama F, et al. Co-opting endogenous immunoglobulin for the regulation of inflammation and osteoclastogenesis in humans and mice. Arthritis Rheum 2011;63:3897-907.

21 Arai F, Miyamoto T, Ohneda 0, et al. Commitment and differentiation of osteoclast precursor cells by the sequential expression of $\mathrm{c}-\mathrm{fms}$ and receptor activator of nuclear factor kappaB (RANK) receptors. J Exp Med 1999;190:1741-54.

22 Dong $X$, Weng $Z$. The correlation between histone modifications and gene expression. Epigenomics 2013:5:113-6.

23 Ichikawa K, Liu W, Fleck M, et al. TRAIL-R2 (DR5) mediates apoptosis of synovial fibroblasts in rheumatoid arthritis. J Immunol 2003:171:1061-9.

24 Redlich K, Hayer S, Maier A, et al. Tumor necrosis factor alpha-mediated joint destruction is inhibited by targeting osteoclasts with osteoprotegerin. Arthritis Rheum 2002;46:785-92.

25 Redlich K, Hayer S, Ricci R, et al. Osteoclasts are essential for TNF-alpha-mediated joint destruction. J Clin Invest 2002;110:1419-27.

26 Li P, Schwarz EM. The TNF-alpha transgenic mouse model of inflammatory arthritis. Immunopathol 2003;25:19-33.

27 Moreland LW, Baumgartner SW, Schiff MH, et al. Treatment of rheumatoid arthritis with a recombinant human tumor necrosis factor receptor (p75)-Fc fusion protein. N Eng/ J Med 1997;337:141-7. 
28 Lee SE, Chung WJ, Kwak HB, et al. Tumor necrosis factor-alpha supports the survival of osteoclasts through the activation of Akt and ERK. J Biol Chem 2001;276:49343-9.

29 Oeckinghaus A, Hayden MS, Ghosh S. Crosstalk in NF- $\kappa B$ signaling pathways. Nat Immunol 2011:12:695-708.

30 Sun S-C. The non-canonical NF- $\kappa B$ pathway in immunity and inflammation. Nat Rev Immunol 2017;17:545-58.

31 Boyce BF, Xiu Y, Li J, et al. NF-אB-Mediated Regulation of Osteoclastogenesis. Endocrinol Metab 2015;30:35-44.

32 Hijdra D, Vorselaars AD, Grutters JC, et al. Differential expression of TNFR1 (CD120a) and TNFR2 (CD120b) on subpopulations of human monocytes. J Inflamm 2012;9:38.

33 Novack DV, Yin L, Hagen-Stapleton A, et al. The $1 \kappa B$ function of NF- $\kappa B 2$ p100 controls stimulated osteoclastogenesis. J Exp Med 2003;198:771-81.

34 Vaira S, Johnson T, Hirbe AC, et al. Relb is the NF-kappaB subunit downstream of NIK responsible for osteoclast differentiation. Proc Natl Acad Sci U SA 2008;105:3897-902.

35 Zhao Z, Hou X, Yin X, et al. Tnf induction of NF- $\kappa B$ RelB enhances RANKL-induced osteoclastogenesis by promoting inflammatory macrophage differentiation but also limits it through suppression of NFATc1 expression. PLoS One 2015;10:e0135728.

36 Jongbloed SL, Lebre MC, Fraser AR, et al. Enumeration and phenotypical analysis of distinct dendritic cell subsets in psoriatic arthritis and rheumatoid arthritis. Arthritis Res Ther 2006;8:R15.

37 Canavan M, Marzaioli V, McGarry T, et al. Rheumatoid arthritis synovial microenvironment induces metabolic and functional adaptations in dendritic cells. Clin Exp Immunol 2020:202:226-38
38 Zhang F, Wei K, Slowikowski K, et al. Defining inflammatory cell states in rheumatoid arthritis joint synovial tissues by integrating single-cell transcriptomics and mass cytometry. Nat Immunol 2019;20:928-42.

39 Smiljanovic B, Radzikowska A, Kuca-Warnawin E, et al. Monocyte alterations in rheumatoid arthritis are dominated by preterm release from bone marrow and prominent triggering in the joint. Ann Rheum Dis 2018;77:300-8.

40 Casazza A, Laoui D, Wenes $M$, et al. Impeding macrophage entry into hypoxic tumor areas by Sema3A/Nrp1 signaling blockade inhibits angiogenesis and restores antitumor immunity. Cancer Cell 2013;24:695-709.

41 Niida S, Kaku M, Amano H, et al. Vascular endothelial growth factor can substitute for macrophage colony-stimulating factor in the support of osteoclastic bone resorption. J Exp Med 1999;190:293-8.

42 Sawano A, Iwai S, Sakurai Y, et al. Flt-1, vascular endothelial growth factor receptor 1 , is a novel cell surface marker for the lineage of monocyte-macrophages in humans. Blood 2001;97:785-91.

43 Hyun $\mathrm{K}$, Jeon J, Park K, et al. Writing, erasing and reading histone lysine methylations. Exp Mol Med 2017;49:e324.

44 Alnaeeli M, Park J, Mahamed D, et al. Dendritic cells at the osteo-immune interface: implications for inflammation-induced bone loss. J Bone Miner Res 2007;22:775-80.

45 Combe B, Lula S, Boone $C$, et al. Effects of biologic disease-modifying anti-rheumatic drugs on the radiographic progression of rheumatoid arthritis: a systematic literature review. Clin Exp Rheumatol 2018;36:658-67. 